\title{
Combined production of electricity and hydrogen from solar energy and its use in the wine sector
}

\author{
Javier Carroquino ${ }^{1,3}$, Vicente Roda $^{2,4}$, Radu Mustata2 ${ }^{2}$ Jesús Yago ${ }^{3}$, Luis Valiño², \\ Antonio Lozano², Félix Barreras ${ }^{2,+}$
}

\footnotetext{
${ }^{1}$ University of Zaragoza, Dep. of Electrical Engineering, Maria de Luna 3, 50018-Zaragoza (Spain)

2 LIFTEC, CSIC-Univ. of Zaragoza, Maria de Luna 10, 50018 - Zaragoza (Spain)

${ }^{3}$ Intergia Energía Sostenible S.L., Av. Cataluña 19, 50014 - Zaragoza (Spain)

${ }^{4}$ Present address: Institut de Robòtica i Informàtica Industrial, CSIC-UPC, Llorens i Artigas 4-6, 08028 - Barcelona (Spain)
}

\section{ABSTRACT}

In the present research, the energy demanded by the wastewater treatment plant of a winery and the pumping station of the irrigation system of a vineyard is supplied by a stand-alone renewable energy system formed by three photovoltaic arrays connected to a microgrid. A relatively small battery maintains the stability and quality of the energy supply acting as a short-term energy storage. Hydrogen is generated in a production and refueling plant specifically designed for this project, and it is eventually used in a plugin BEV properly modified as a hybrid vehicle by adding a PEM fuel cell. On the one hand, the technical and economic feasibility of the on-site electricity production for the winery and vineyard, compared to the commercial electricity from the grid and diesel gensets, is demonstrated. On the other hand, the diesel savings by the hydrogen generated on site are assessed. The electricity $(72 \mathrm{MWh})$ and hydrogen $\left(1,214 \mathrm{~m}^{3}\right)$ produced in the first year have saved the emission of around 27 tons of equivalent $\mathrm{CO}_{2}$.

Keywords: Power-to-gas; Renewable energy; Solar PV energy; Hydrogen; PEM fuel cell; Hybrid electric vehicle

\footnotetext{
† Corresponding Author: felix@litec.csic.es Ph.: (+34) 976506 520. Fax: (+34) 976506644
} 


\section{NOMENCLATURE}

\section{Acronyms}

ATEX Anti-explosion elements

BEV Battery electric vehicles

$\mathrm{CO}_{2}$-e equivalent $\mathrm{CO}_{2}$

ECU Electronic control unit

EM Electric machine of the BEV

EMS Energy Management System

FC Fuel cell

FCHEV Fuel cell hybrid electric vehicles

GSS Gas storage system

HEV Hybrid electric vehicle

HPP Hybrid power plant

HRES Hybrid renewable energy systems

IRR Internal rate of return (\%)

$\mathrm{NI} \quad$ National Instruments

NPV Net present value $(€)$

OS Operative system

PEM Polymer electrolyte membrane

PLC Programmable logic controller

PV Solar photovoltaic

PWM Pulse-width modulation

RES Renewable energy sources

$\mathrm{SOC}$ State of charge of the battery

TAC Total annual costs

WWTP+IS Waste water treatment plant and irrigation system

\section{Latin symbols}

$A E \quad$ Annual expenses $(€)$

C Cash-flow

CoE Energy cost $(€)$

$\mathrm{CoL}$ Cost due to lifetime $(€)$

CoP Power cost $(€)$

E Energy consumed (kWh)

lo Initial investment costs $(€)$

Inf Inflation (\%)

$k \quad$ Discount rate

P Power consumed (kW)

\section{Subscript}

Bat Battery system

CE Commercial energy

DG Diesel generation set

Gen General

Inv Inverters

PV $\quad$ PV solar plant 
Increasing the use of renewable energy sources (RES) in the energy mix has become a challenge for power engineers and scientists all over the world. Even when hybrid power systems based on RES (HRES) have attracted the attention of the sustainable energy market, the optimal use of either solar photovoltaic (PV) or wind power is difficult, specifically in local power grids. This is because of their fluctuating and intermittent nature, due to the dependence on meteorological conditions. Thus, standalone renewable energy sources cannot guarantee a reliable power supply. A typical solution to this problem is the use of HRES combining both short-term energy storage options (batteries, capacitors, flywheels, or compressed air) and long-term ones with hydrogen as energy storage. Hydrogen is considered the energy vector of the future, especially if it is produced from RES [1-5]. Different energy storage systems have been used to optimize the energy management of power systems based on single or multiple RES in the household sector, in applications such as plug-in battery electric vehicles (BEV) [6] or fuel cells [7-10].

In remote rural areas, the energy demand can be actually satisfied using HRES, but their introduction has been limited by the lack of economic viability and technical adaptation. Aerial power lines, which are very expensive, are normally extended in natural areas to distribute commercial electricity to the consumers. These infrastructures have a severe environmental impact affecting the skyline and, what is more important, killing both native and migratory birds, something especially serious in the case of endangered species. In the particular case of the wine industry, energy demands (irrigation, farming machinery, thermal processes, mobility, etc.) present strong seasonal cycles not only throughout the year but also during the day. Besides, fossil fuels are massively used both in transportation and on-site power generation, emitting $\mathrm{CO}_{2}$ and other pollutants. Thus, in order to achieve standalone HRES with high reliability, which would contribute to their massive use in the wine sector, both shortterm and long-term energy management systems must be considered [11,12].

In this research, a part of the energy demanded in a winery is supplied by the power produced from a PV energy system. Specifically, it includes the power consumed by the wastewater treatment plant (aerators), the pumping system for sludge, filtering and irrigation processes, a hydrogen production and refueling station, and the recharge of 
the battery system of an electric vehicle. To the authors' knowledge, this is the first time that such challenge is assumed in this specific sector, which is very relevant for the European countries of the Mediterranean area (Italy, France, Greece, Spain, Portugal, etc.). The research describes in depth the design and operational tests performed during the demonstration period of the PV system and the hydrogen production and refueling station. Besides, the performance of a BEV suitable modified into a hybrid electric vehicle (FCHEV) equipped with a polymer electrolyte membrane fuel cell (PEMFC) is also discussed.

\section{Description of the different facilities}

This research is part of the project "Profitable Small Scale Renewable Energy Systems in Agrifood Industry and Rural Areas: Demonstration in the Wine Sector" [13], funded by the European Union under the LIFE program.

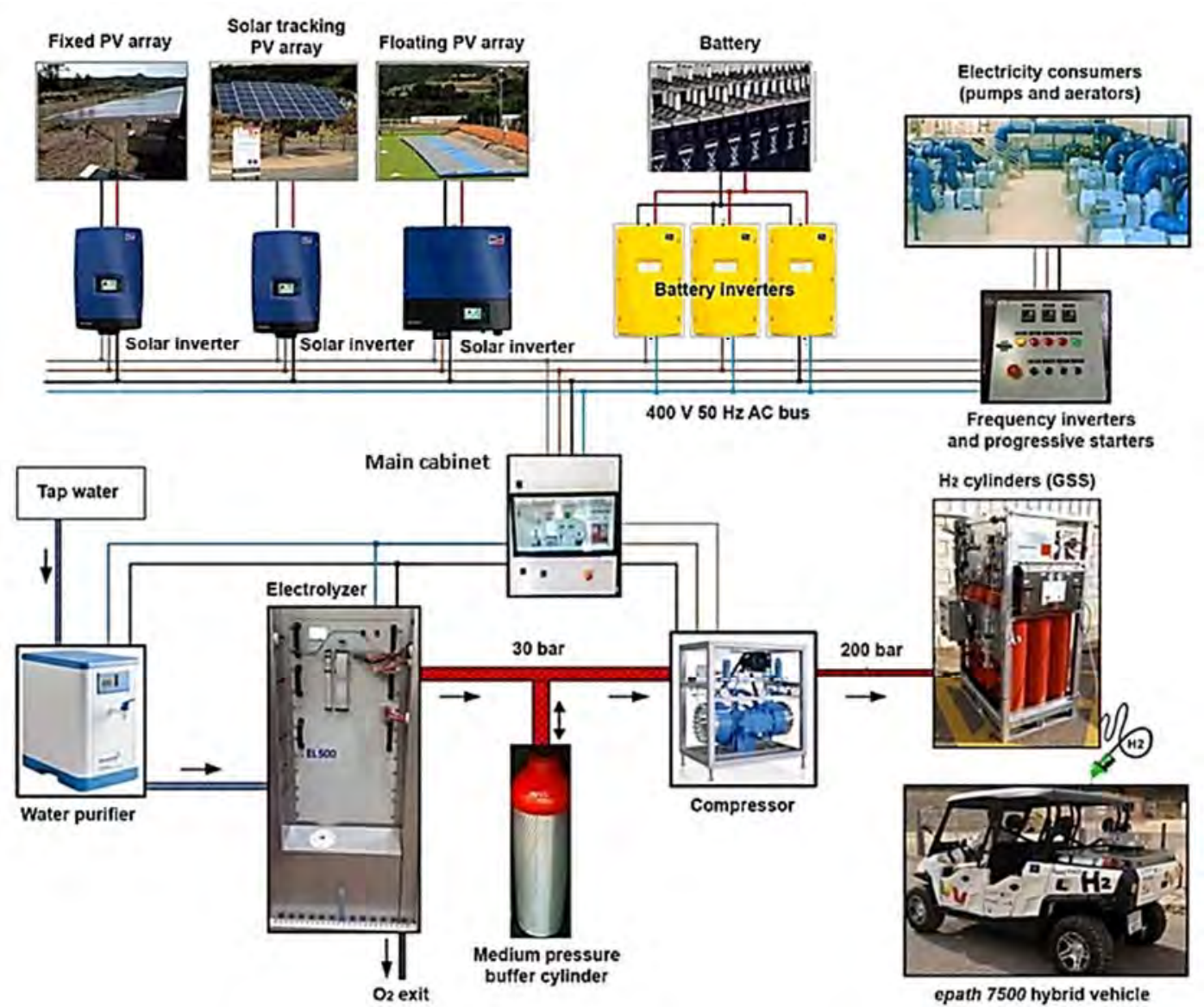

Figure 1. General scheme of the power-to-gas plant of this project

The project facility is placed at Viñas del Vero winery, which is located in the Somontano region, in the north of Aragon (Spain). As depicted in Fig. 1, this power-to- 
gas power plant is formed by two main facilities: the electricity production section (upper row) and the hydrogen production and storage units (lower row). They are interconnected by a main cabinet where all the control and safety software are installed. The surplus electricity produced by a solar PV plant is converted into hydrogen by water electrolysis. The hydrogen produced is stored in pressure cylinders and is further reconverted into electricity in a PEMFC that is the secondary power source of the hybrid power plant of a FCHEV.

\subsection{The electrical facility}

The energy consumed by the wastewater treatment plant and the irrigation system (WWTP+IS), which was originally connected to the main winery electric grid, has been replaced by a solar PV plant and a microgrid formed by battery storage system. As depicted in Fig. 1, the stand-alone electrical facility is formed by the PV plant, a battery that acts as the short-term energy storage system, different inverters to properly use the electricity, and the consumer elements. The water used for irrigation is recycled from the wine production processes. The wastewater is accumulated in an aeration pond where it is treated, and is sequentially moved using centrifugal pumps to the filtration sandbox and to the irrigation pond. The vineyards to be irrigated have an area of $10 \mathrm{ha}$, and the annual water volume used for this purpose reaches $10,000 \mathrm{~m}^{3}$ [14]. The power consumed and tasks performed by the different consumers are summarized in Table 1.

\begin{tabular}{|c|c|c|c|}
\hline Consumers & Qty & Tasks & Total Power (kW) \\
\hline Aerators & 2 & $\begin{array}{l}\text { Injecting air bubbles to activate the } \\
\text { biodegradation of the waste water }\end{array}$ & 28 \\
\hline Elevation pumps & 2 & $\begin{array}{l}\text { Moving the treated water from the } \\
\text { different ponds }\end{array}$ & 9.8 \\
\hline Irrigation pump & 1 & $\begin{array}{l}\text { Irrigating the vineyard during the } \\
\text { irrigation season ( } 123 \text { days) }\end{array}$ & 11 \\
\hline Sludge pumps & 2 & $\begin{array}{l}\text { Moving the sludge from aeration } \\
\text { pond to the sludge one }\end{array}$ & 3.6 \\
\hline
\end{tabular}

Table 1. Summary of the electrical loads of the WWTP+IS

Among the different possible RES, only solar and wind power were initially considered, since there are no other reliable resources in the area. However, wind 
power was discarded due to the small average air velocity $\left(1.66 \mathrm{~m} \mathrm{~s}^{-1}\right)$ measured during on-site measurement campaigns [15]. On the contrary, solar power is a very reliable option due to the high average solar irradiance in Spain [16]. The average value corresponding to the exact location of the winery, obtained from the Photovoltaic Geographical Information System (PVGIS) of the European Union [17], is $4.73 \mathrm{kWh} \mathrm{m}^{-2}$ day $^{-1}$, as can be observed in Fig. 2. The maximum value takes place in Summer, concurring with the irrigation season, and it is well above $7.5 \mathrm{kWh} \mathrm{m}^{-2} \mathrm{day}^{-1}$. In addition, optimal inclination according to PVGIS varies between $9^{\circ}$ in June and $66^{\circ}$ in December, with an annual average value of $37^{\circ}$.

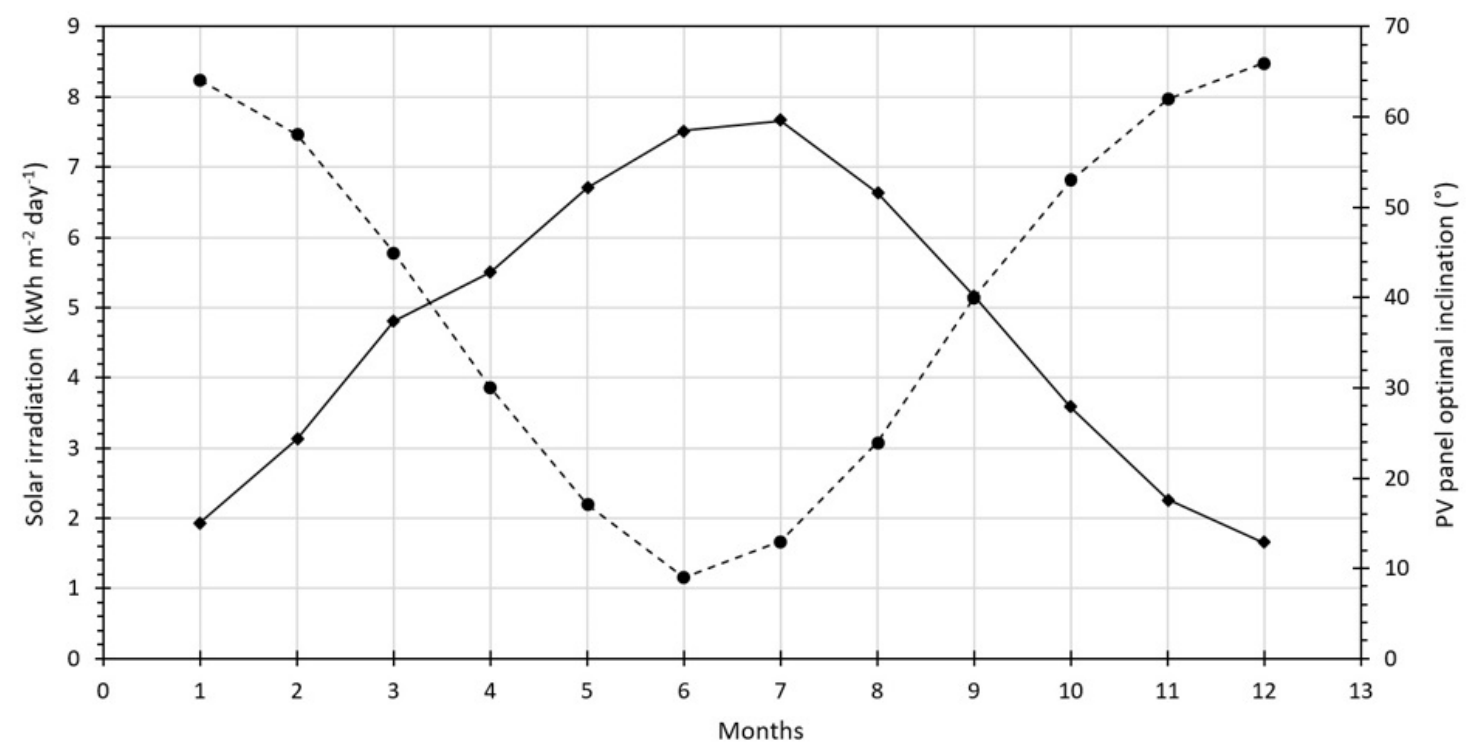

Figure 2. Estimated values of solar irradiation (solid line) and optimal panel inclination (dashed line) for each month at the winery area [25]

\subsubsection{The solar photovoltaic system}

The use of solar energy within the energy mix is common in many countries all over the world [18-23]. However, the indisputable role of solar energy in the Twenty-first Century is overshadowed by the intermittent nature of its power production. This problem can be addressed by the use of both short-term and long-term energy storage systems [24-29]. Although conventional stand-alone solar systems often use a DC bus architecture, it was decided to design a system with an AC bus, to which both PV inverters and power consumers are connected. So, the electric power produced by the PV panels can be directly used by the different AC consumers using DC/AC solar power inverters, increasing the efficiency of the electric system, and reducing the battery size. 


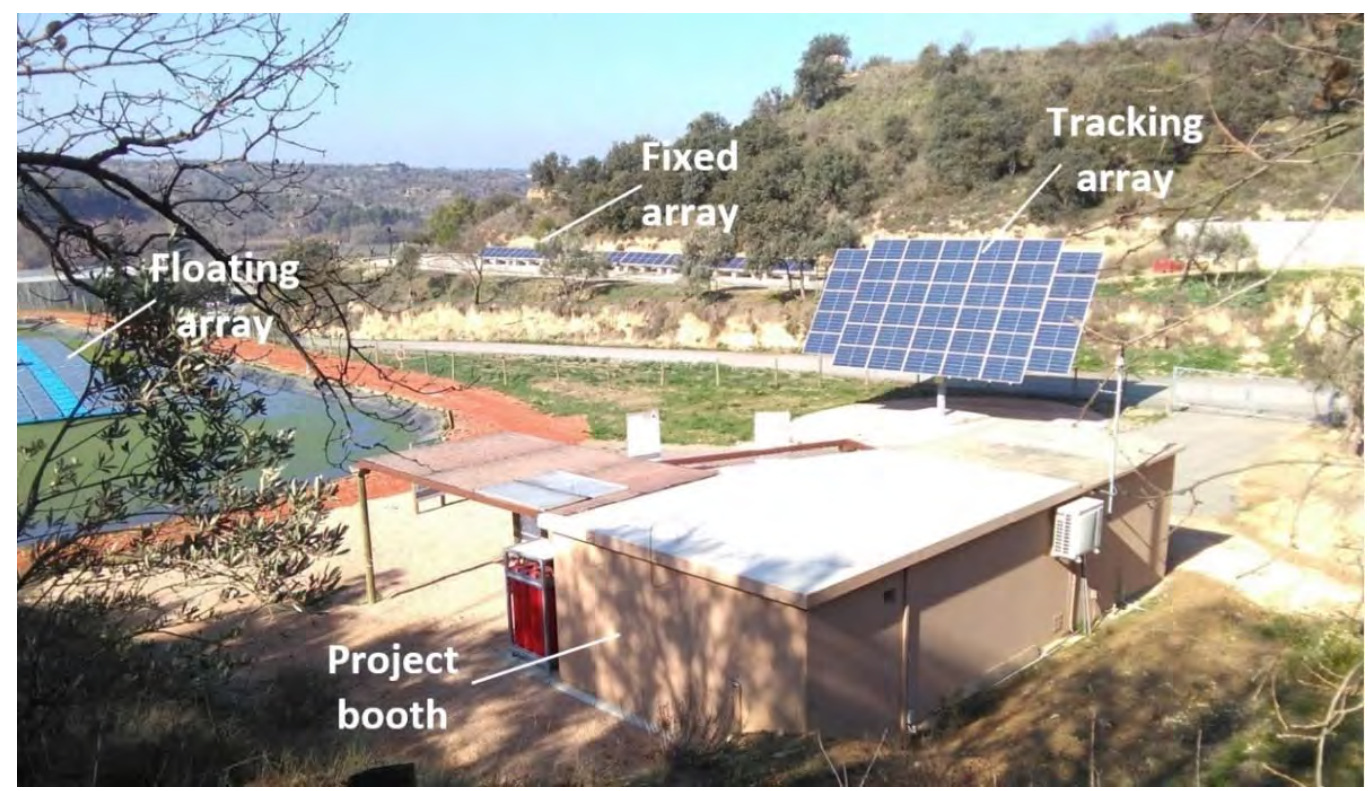

Figure 3. Assembling of the different solar arrays and main project booth at the WWTP+IS area

There are several computational tools to assist the design and analysis of HRES and microgrids, such as the Hybrid Optimization Model for Electric Renewables (HOMER), improved Hybrid Optimization by Genetic Algorithm (iHOGA), and Hybrid2, which implement quantitative methods. In the present research, to optimize the design and performance of the system in terms of efficiency and reliability, iHOGA was used. In essence, this software tool incorporates the Ah ageing model to optimize the HRES, and takes advantage of genetic algorithm characteristics to enhance the whole optimization process, giving good results in a short computational time [30]. The power plant includes three sets of PV panels, in order to show different assembling options and to carry out comparative studies: a fixed structure located on the sandbox, a solar tracker, and a floating set placed on the surface of the aeration pond. The location of all PV arrays in the WWTP+IS area is indicated in Fig. 3. All of them are commercial (multicrystaline) polysilicon TP 265/275 Wp model PV panels manufactured by REC, which have a conversion efficiency of $16.1 \%$ and $16.7 \%$, respectively. A summary of the main data of the three technologies is presented in Table 2. Regarding to the fixed structure, the tilt of the PV panels can be set to $5^{\circ}$ or $30^{\circ}$ in order to adapt the profile of the incident solar irradiation to the different energy seasonal profiles. With respect to the floating PV array, it should be noted that a remarkable advantage of the decision to place it over the surface of the aeration pond is that the performance of the panels is increased when 
116 its working temperature is decreased. In addition, both evaporation of water and 117 proliferation of algae in the pond are also reduced. In summary, the total solar power 118 installed reaches $43.2 \mathrm{kWp}$.

\begin{tabular}{llcc}
\hline Array & \multicolumn{1}{c}{ Supporting structure } & Tilt & PV power (kWp) \\
\hline Fixed & Metallic structure on the ground & $5^{\circ}$ or $30^{\circ}$ & 10.8 \\
Tracking & Two-axis solar tracker & - & 10.8 \\
Floating & Structure designed for this application & $5^{\circ}$ & 21.6 \\
\hline
\end{tabular}

Table 2. Main characteristics of the different arrays forming the solar PV plant

The variable voltage and intensity DC produced by the PV panels is converted to three-phase AC (400 V, $50 \mathrm{~Hz})$ using three DC/AC Sunny Tripower (STP) PV solar inverters from SMA. Their electrical connection to the main AC bus is depicted in Fig. 1.

\subsubsection{The battery storage system}

The total energy produced by the solar PV facility normally exceeds the needs of the WWTP+IS. A short-term storage system allows energy to be available at any time of the day and at night, regardless of the generator instantaneous production. It consists in a lead-acid battery bank with 24 solar.power OPzS 3610 cells manufactured by Hoppecke, with a capacity of 2,680 Ah (128.64 kWh). They are formed by tubular plates with liquid electrolyte, suitable for this application since ultra-fast discharge regimes are not expected. Three Sunny Island SI-8.0H battery inverters from SMA (one for each phase) are used to produce a $400 \mathrm{~V} 50 \mathrm{~Hz}$ microgrid and to correctly manage the battery charge and discharge processes. Their electrical connection to the main AC bus can be observed in Fig. 1. The battery storage system provides flexibility to the facility by storing the excess energy to be consumed later during the periods of lack and/or low renewable energy production.

There are several factors that affect the initial investment and maintenance costs of the battery. The variability of the solar PV system and the operating philosophy can impose stress conditions that eventually reduce its lifetime. On the one hand, the smaller the size of the battery bank the higher the cost effectiveness of the whole system. On the other hand, the lifetime of lead-acid batteries depends on the depth of discharge and the number of cycles. Lowering a state of charge (SOC) below $20 \%$ can be very harmful. For this reason, a key point when designing this HRES was to reduce the 
amount of energy to be stored in the battery bank. It is for this reason that in this system the capacity of the battery bank was not calculated to provide a large autonomy, but to match the production and consumption in an intraday regime, with a small depth of discharge. On the contrary, on days with low PV production, a deeper discharge cycle is possible, but this situation is very uncommon. The actual SOC of the battery is calculated by the charge controller with an accuracy of $95 \%$ by combining the direct measurement of the in-flowing and out-flowing current with a current voltage model.

\subsubsection{Energy management system and control strategy}

The implementation of an energy management system (EMS) is required both to avoid failures due to the lack of available energy and to minimize losses when it cannot be used nor stored [29]. It is noteworthy that much of the consumption of the system can be deferred. Consequently, the loads can be activated when there is PV energy production and deactivated when the battery has a low state of charge. To maximize the output power from the PV modules to the direct consumers, the maximum power point (MPP) control unit is employed [31]. To this end, a fuzzy logic control is used for the solution of the different options of the nonlinear system. The system is managed in such a way that the energy is consumed, if possible, when it is generated, avoiding its cycling in the battery. As a result, the energy stored is largely reduced, minimizing the inherent losses for $A C$ to $D C$ to $A C$ conversion in the battery inverters and those for the battery charge and discharge processes.

The EMS designed in this project optimizes the match between the load demand and the energy generated by the RES at every time. For this purpose, several decisions were adopted in order to establish the priorities between the use of the different consumers and the production of hydrogen during each day, taking into account the different seasons of the year. Different sensors measure the solar irradiation, the energy production, and the SOC of the battery, among other variables. With all of them, the EMS activates or deactivates the different loads. Finally, as far as energy efficiency is concerned, the electric motors of the different loads are driven by commercial variable frequency drivers. Thus, the aerators and the pumps not only work at the optimum working point of their load curve, but also current peaks are avoided, smoothing their mechanical and electrical operation and enlarging its useful lifetime. 

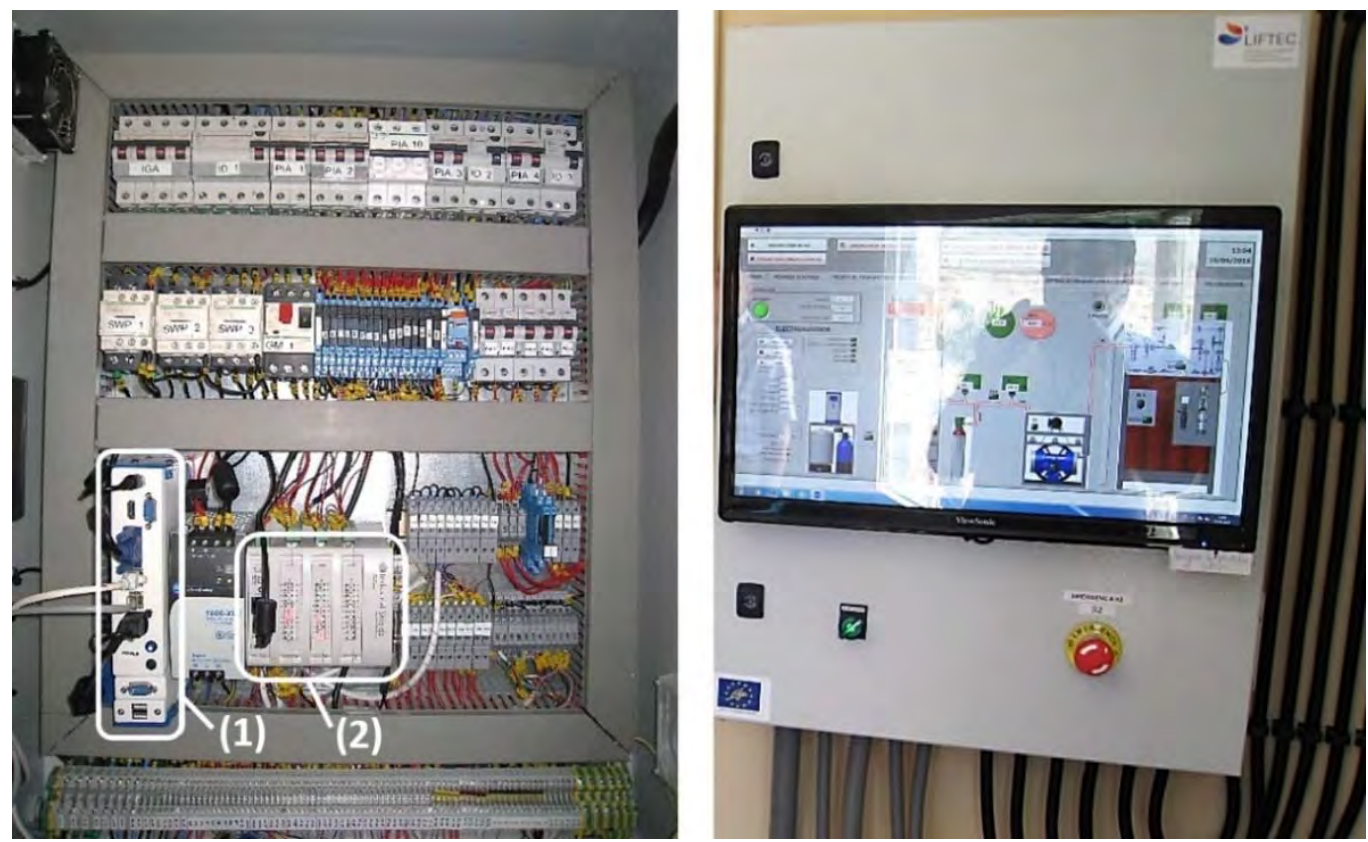

Figure 4. Inside (left) and outside (right) images of the main control cabinet

The control and safety software is loaded in a computer inside the main cabinet that interconnects the electrical and hydrogen facilities. Two pictures of the inner and outer sides of this cabinet are depicted in Fig. 4. All the decisions adopted are included in the NI LabView ${ }^{\circledR}$ control software that runs on an industrial computer with Windows 7 OS. It is an ultracompact Epatec IPC computer (number 1 in Fig. 4) with a fast Intel Celeron 1.8 GHz Quad Core processor. The Arduino PLC automata (number 2 in Fig. 4) is a Mduino $57 \mathrm{R}$ with an ATmega2560 microcontroller and a clock speed of $16 \mathrm{MHz}$. It has 18 input ports (12 for analog/digital signals, and 6 interrupt switches), as well as 39 output points ( 8 analog signals, 23 digital ones, and 8 PWM isolated 8 bit). Users can interact with the control and supervision system through a commercial touch screen. The visualization software shows the status of the installation using different windows that can be easily displayed. Remote access via internet is also possible.

\subsection{The hydrogen facility}

In addition to the short-term energy storage battery, in the present project hydrogen is used as a long-term storage system. It should be noted that here, contrary to the most common solution where the stored energy is reverted to the same system, hydrogen energy is used to refuel a plug-in BEV properly modified to a hybrid one using a PEM fuel cell. The hydrogen facility is formed by a production and refueling plant and the FCHEV that is the end-user of the produced hydrogen. 


\subsubsection{The hydrogen production and refueling plant}

The hydrogen generation and refueling station (see Fig. 5) has been specifically designed for this research. The system is mainly composed by a compact water purification system (1), an alkaline electrolyzer (2), a metal diaphragm compressor (3), and a stationary gas storage system (4), and a medium-pressure buffer aluminum cylinder from Luxfer with a water volume of 10 liters (5) which is placed just in between the electrolyzer and the compressor. The main characteristics of these equipment are summarized in Table 3.

\begin{tabular}{|c|c|c|c|}
\hline Equipment & Manufacturer & Technology & Characteristics \\
\hline $\begin{array}{l}\text { Ecomatic water } \\
\text { purification system }\end{array}$ & Wasserlab & Reverse osmosis & $\begin{array}{l}\text { Flow: } 3 \text { I } \mathrm{h}^{-1} \text {; } \\
\text { Conductivity: }<5 \mu \mathrm{sm}^{-1}\end{array}$ \\
\hline Electrolyzer EL-500 & Heliocentris & $\begin{array}{l}\text { Alkaline Exchange } \\
\text { Membrane (KOH) }\end{array}$ & $\begin{array}{l}\text { Flow: } 500 \mathrm{NI} \mathrm{h}^{-1} @ 30 \\
\text { bar; Purity: } 99.999 \%\end{array}$ \\
\hline $\begin{array}{l}\text { Compressor } \\
\text { MV6208 }\end{array}$ & Sera & $\begin{array}{l}\text { Metal-diaphragm, } \\
\text { double-stage }\end{array}$ & $\begin{array}{l}\text { Flow: } 500 \text { NI h }{ }^{-1} @ 200 \\
\text { bar }\end{array}$ \\
\hline
\end{tabular}

Table 3. Equipment of the hydrogen production plant

All equipment, devices and elements for the hydrogen production plant are installed in an isolated room inside the project booth, while those corresponding to the storage and refueling station are placed outside. To avoid possible accidents, all elements and devices fulfill the anti-explosion (ATEX) regulations required for any hydrogen facility. A detector for hydrogen leaks (7), and a temperature sensor (8) are also assembled to ensure the safe operation of the facility.
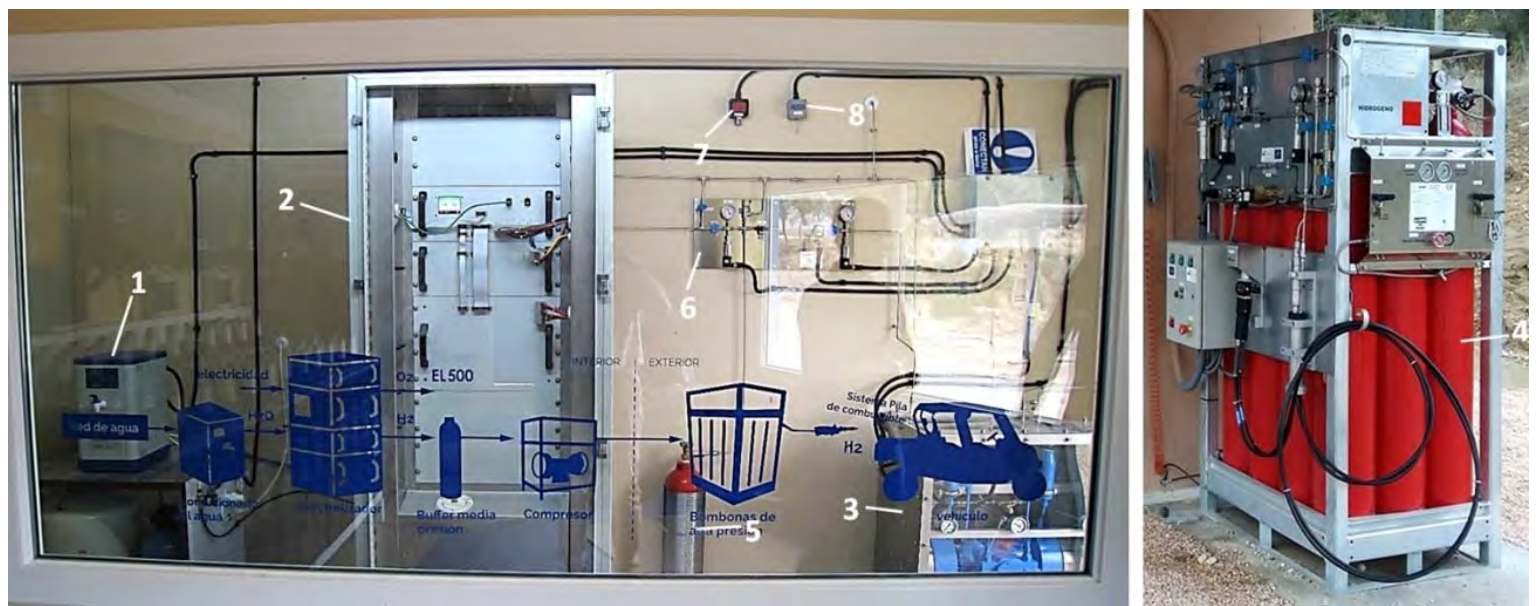

Figure 5. Hydrogen production and refueling plant. Pictures of the production devices assembled inside the booth and the stationary GSS placed outside (right) 
The flow diagram of the control panel (number 6 in Fig. 5) can be observed in Fig. 6. It is formed by two check-valves (ChV1, ChV2) for the correct circulation of hydrogen, two manometers (M1, M2) to visualize the pressure just after the electrolyzer and before the compressor, respectively, and three manual valves (MV1, MV2, MV3) that are assembled for security.

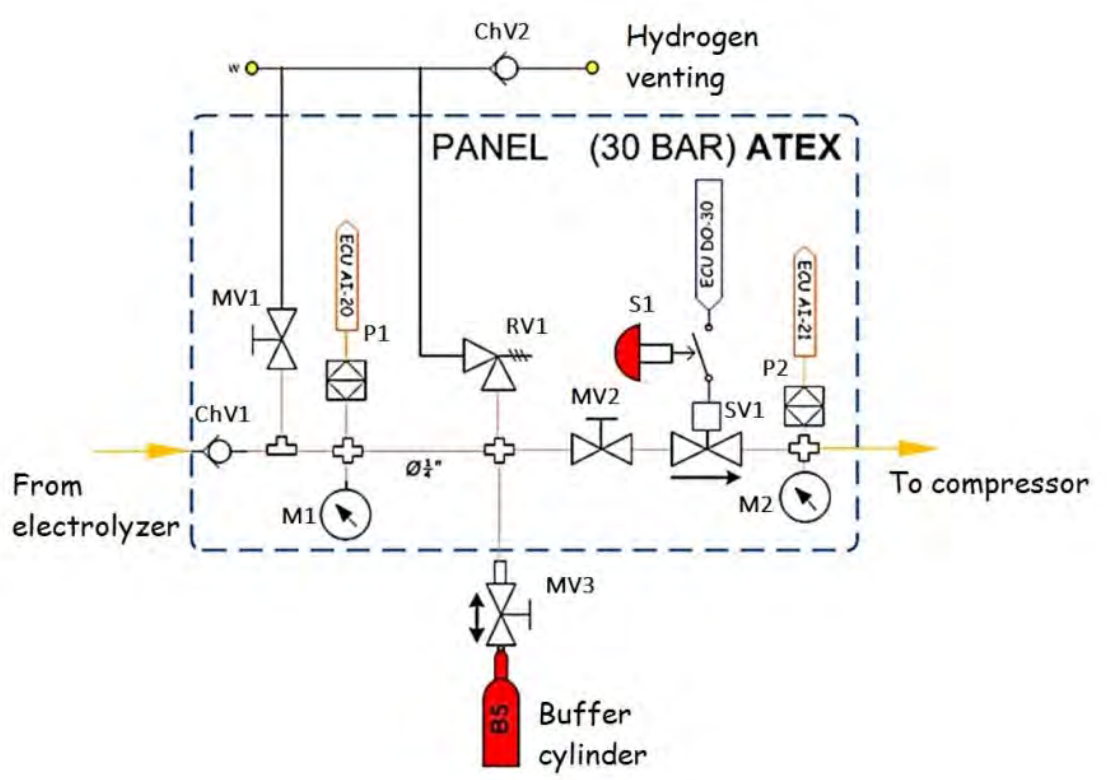

Figure 6. Panel used to control the correct performance of the compression stage

The safe operation of the compressor is controlled by the electrical signal provided by the solenoid valve SV1 that takes the pressure reference from pressure transducers $\mathrm{P} 1$ and $\mathrm{P} 2$. It is turned on when the pressure at $\mathrm{P} 2$ raises to 29.5 bar and turns off when it falls below 15 bar. The panel also includes an automatic hydrogen release valve (RV1) that is activated when the pressure at the inlet point (P1) is above 45 bar.

The hydrogen plant also includes a stationary gas storage system (GSS) formed by a rack with 12 cylinders, with a water volume of 50 I each. Thus, it can store $106 \mathrm{~m}^{3}(9.53$ $\mathrm{kg}$ ) of hydrogen at 200 bar. The $\mathrm{H}_{2}$ stored at the stationary GSS is automatically supplied to the FCHEV with a commercial WEH ${ }^{\circledR}$ refueling system. It is formed by a TK-16 nozzle and a TN-1 receptacle, and integrates a high-flow check valve and a $20 \mu \mathrm{m}$ self-cleaning particle filter. The WEH system has also a breakaway coupling that cuts off the hydrogen connection panel with its corresponding control electronics was specifically designed and built for this application. It is placed on one side of the GSS, and a photo and the corresponding flow diagram is depicted in Fig. 7. It is formed by a coalescent filter (F1), 
and different check (ChV3, ChV4) and release valves (RV2, RV3, RV4). As a novelty, it has been designed both to refill the stationary GSS with hydrogen from the compressor (red lines) and to discharge it to refuel the GSS of the FCHEV (blue lines). Thus, some pipes of this panel are indistinctly used both for charge and discharge processes. The correct circulation of the gas is controlled by the solenoid valve SV2. The electrical signal to activate SV2 when refueling comes from the supplying switch placed at the control panel. The overflow valve, OV1, cuts off the hydrogen flow if an unexpected high value is detected providing an extra safety to the facility. This valve also moderates the flowrate when the solenoid valve SV2 is opened to refuel hydrogen to the GSS of the FCHEV.

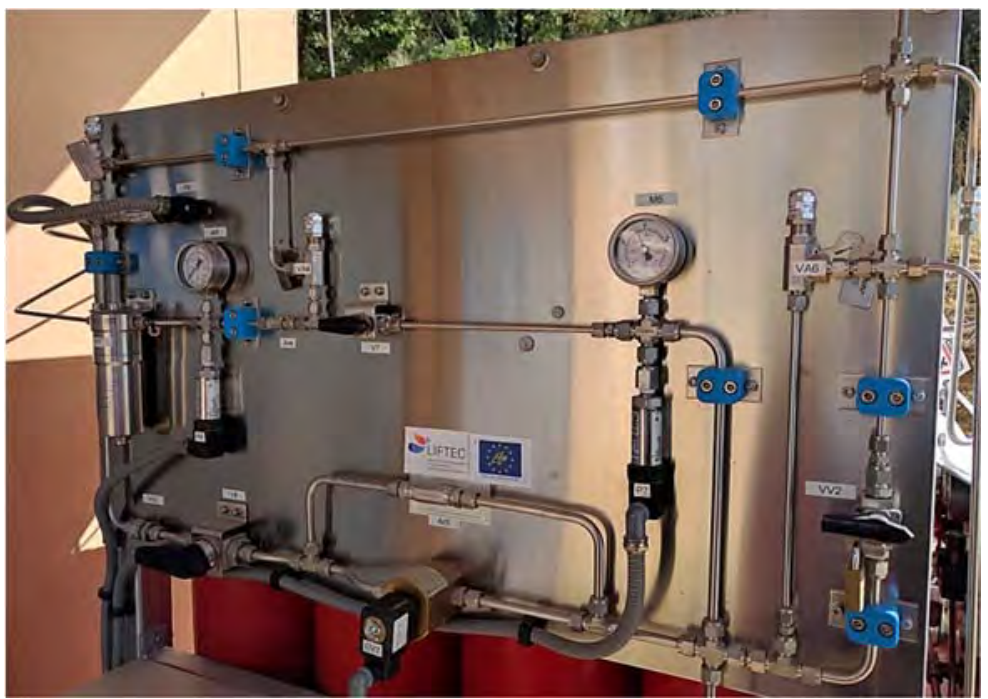

a)

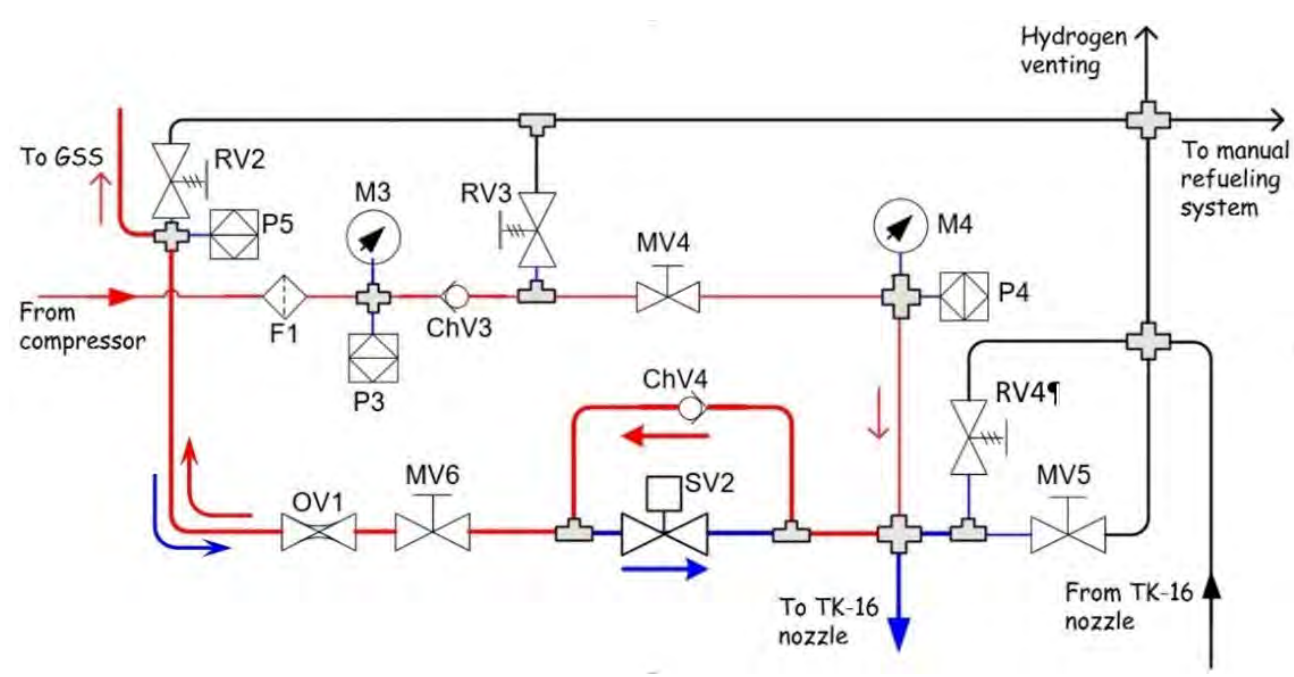

b)

Figure 7. Panel used to refill the stationary GSS and to refuel hydrogen to the FCHEV 


\subsubsection{The PEMFC hybrid electric vehicle (FCHEV)}

The end-user of the hydrogen system is a commercial ePath-7500 electric car manufactured by EMC (see Fig. 8 a), suitably modified to be powered by a hybrid powertrain based on PEM fuel cell and batteries. This is an all-wheel drive 4-seat vehicle designed to travel on bumpy and irregular terrain, ideal for agricultural or industrial tasks. Originally, the $7.5 \mathrm{~kW} 72 \mathrm{~V}$ electric motor of the car was powered by a set of 12 gel-type 6 V 225 A-h batteries. The EM is connected to the main DC bus through a DC/AC booster electronic converter. The PEM fuel cell stack with its corresponding GSS, and the electronic devices used for hybridization were assembled at the tilting rear load platform, as shown in Fig. 8 b).

A commercial Horizon $\mathrm{H}-3000$ PEMFC stack, with a rated power of $3 \mathrm{~kW}$, was included as the second power source in the HPP. This is an open-cathode stack formed by 72 cells and graphite bipolar plates that includes 4 axial fans that supply the air flow needed for both the electrochemical reactions and to cool the stack down to the working temperature $\left(50-65^{\circ} \mathrm{C}\right)$. At the rated power $(70 \mathrm{~A}, 43.2 \mathrm{~V})$, the gross efficiency is $47.4 \%$, which decreases to $41.8 \%$ (net) when power consumed by the ancillary systems are considered. The GSS of the FCHEV is formed by four 10 I Luxfer aluminum cylinders, which can store $0.64 \mathrm{~kg}\left(7.12 \mathrm{Nm}^{3}\right)$ of hydrogen when compressed at 200 bar. The supplying system includes a recirculation system formed by a proportional solenoid valve and an ejector that allows to recirculate part of the unreacted hydrogen from the anode sides.

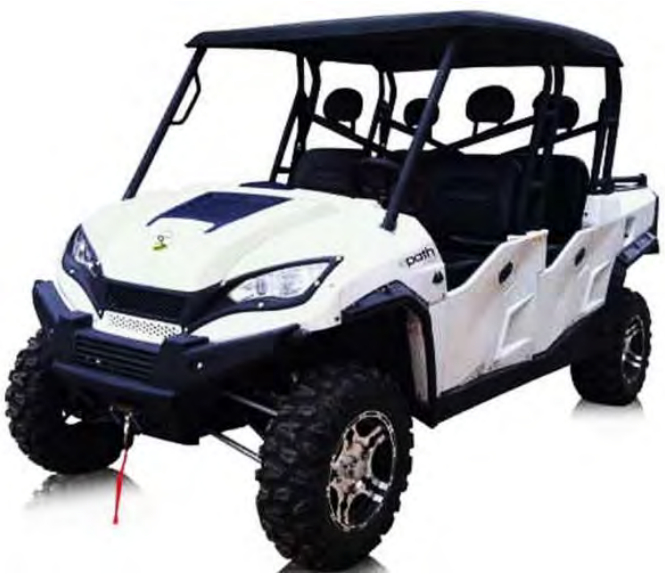

a)

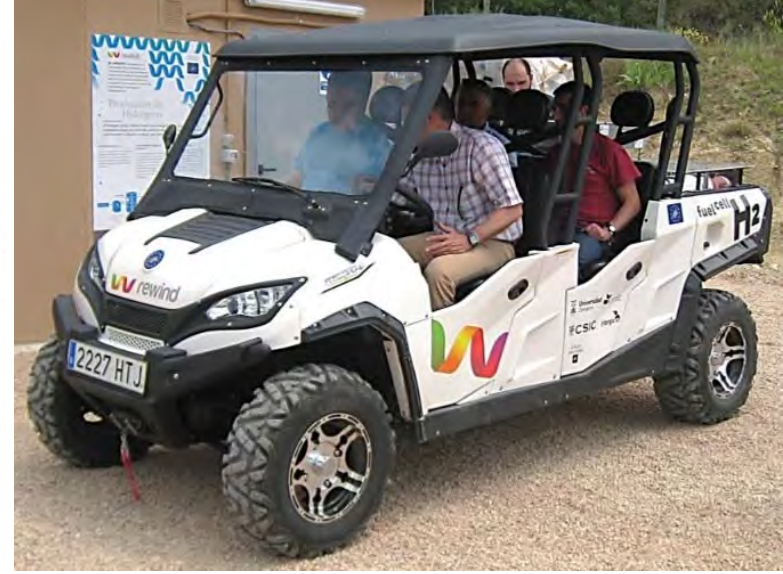

b)

Figure 8. The original ePath $7500 \mathrm{BEV}(\mathrm{a})$, and the remodeled FCHEV (b) 
The active HPP of the FCHEV is formed by a booster DC/DC power converter that supplies the electric power from the PEMFC stack to the main DC bus, and two other DC/DC converters that deliver power to the different elements of the ancillary systems at $12 \mathrm{~V}$ and $24 \mathrm{~V}$. To control and monitor the different electrical parameters of the $\mathrm{H}_{2}+$ PEMFC system, a NI roboRIO microcontroller with a sampling frequency of $800 \mathrm{~Hz}$ was used as the central electronic control unit (ECU). The control system includes as a novelty in fuel cells, a discrete state machine model programmed in LabVIEW with LINUX realtime operating system, which was embedded into the ECU microcontroller [32]. Basically, there are two main operation states. When the vehicle operates in a low consumption rate and the SoC of the battery is below 95\%, the stack is switched to CHARGING mode. In this case, the excess of energy produced by the stack is sent to recharge the battery. On the contrary, if the power demanded at the main DC bus increases, it is shifted to the SUPPLY POWER mode, providing around $30 \%$ of the total power demanded by the EM of the FCHEV. To check the correct operation of the stack, a typical polarization curve was also recorded into the ECU. If the PEMFC stack works properly, it alternates between CHARGING and SUPPLY POWER modes. But, if for a given current it is detected that the voltage delivered by the stack differs by $10 \%$ from the value of the recorded polarization curve, it is moved to the REHABILITATION mode. In this case a purging sequence is activated in order to remove the water accumulated inside the stack since the commercial H-3000 operates in anode dead-end mode. Usually, after the purging sequence the performance of the stack is recovered and it is again moved to SUPPLY POWER or CHARGING modes, depending on the total power demanded by the vehicle. Otherwise, the stack is eventually shifted to the FINISH mode, stopping the hybrid control sequence.

\section{Results}

The system described in this paper was fully installed by the end of May 2016, and the main results obtained in this year are discussed below.

\subsection{Performance of the electric system}

The performance of the PV/electric system for two typical sunny days, one out of the irrigation season, and another within it, are depicted in Figs. 9 and 10, respectively. 


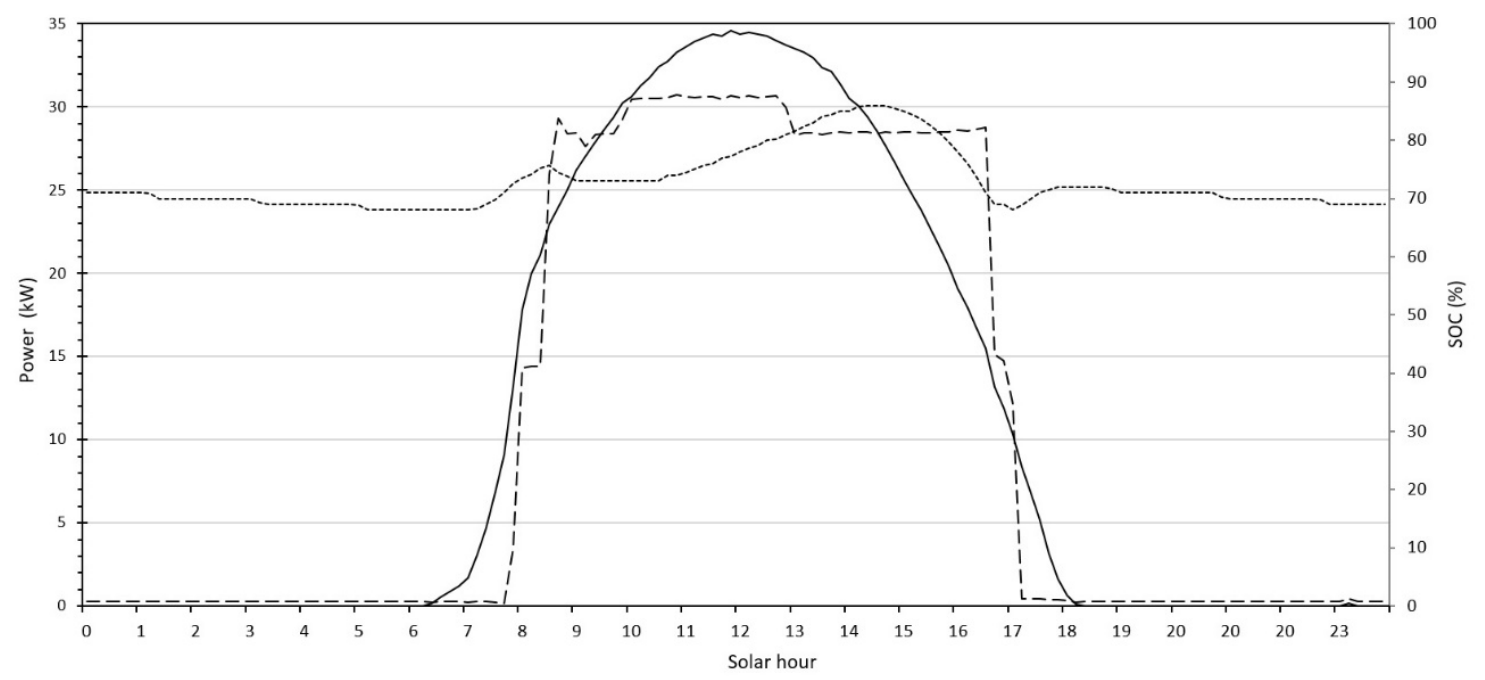

Figure 9. Electric performance during March $19^{\text {th }} 2017$, a day out of the irrigation season. Solid line for power production, dashed for consumption, and dotted one for the SOC of the battery bank

On the one hand, out of the irrigation season, virtually all loads are managed by the system automatically. Thus, the loads are connected during the day, obtaining the maximum simultaneity between generation and consumption of energy, as shown in Fig. 9. It is verified that the energy demand is suitably adapted to the energy production. Only the area not shared by both the production and consumption curves corresponds to the energy charged or discharged from the battery. This represents a very small fraction of the total, minimizing the energy cycled in the battery and the associated $A C / D C$ and $D C / A C$ conversions, avoiding their corresponding losses. The battery absorbs the small intra-day differences of production and consumption, with SOC variations less than $18 \%$, and also maintains its high level of charge which allows the system to work in cloudy days. The average level of SOC (73\%) has not been set too high, since no night consumption is expected and in anticipation of being able to store energy if the loads are disconnected part of the day for some reason.

On the other hand, during the irrigation season, the irrigation is scheduled by the vineyard managers, depending on the needs of vine growing. The control system prioritizes these consumptions and adapts the other ones according to the availability of energy. The system manages the other loads automatically. In Fig. 10, the main nocturnal consumption corresponds to the irrigation system. During the first few hours of sunshine in the morning, a part of the energy produced is used to recharge the 
battery, compensating for the nighttime consumption. The rest of the day, once the SOC of the battery is reestablished, the demand is again well-matched to the production of energy. The SOC variations are less than $35 \%$, and the level of charge is high, which allows the system to work during the night or in cloudy days. The average level of SOC $(76 \%)$ is similar to that obtained outside the irrigation season, but at sunset it is above $90 \%$, waiting for the night consumption.

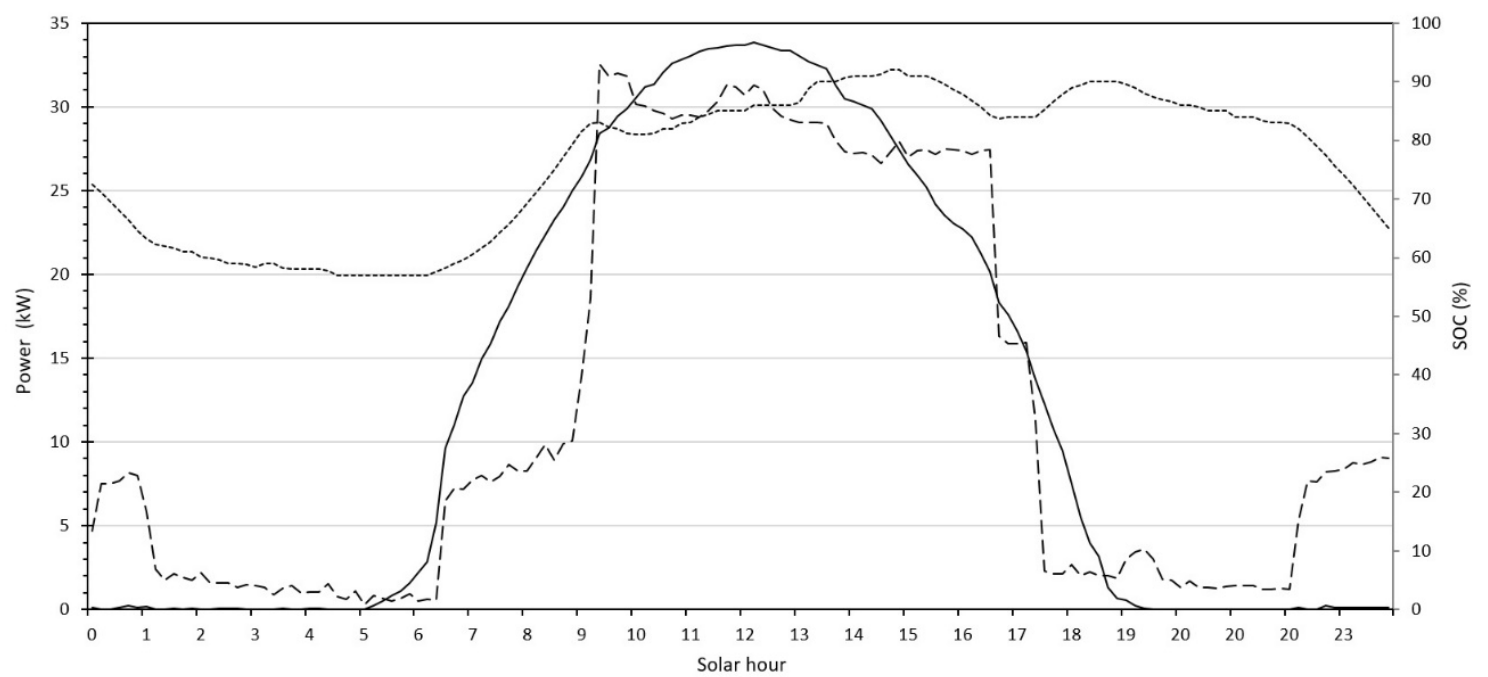

Figure 10. Electric performance during July $28^{\text {th }}, 2017$, a day within the irrigation season. The legend is the same as in Fig. 9

During the first year the actual electricity produced by the PV system was 71.9 MWh. Part of that energy was used for the different consumers of the WWTP+IS (62.15 $\mathrm{MWh}$ ), and 6.4 MWh was employed to produce hydrogen. The energy losses in the system, including those caused by the charge and discharge of the battery bank, have been only $4.76 \%$. This is a very good performance, due to the optimized management strategy. To estimate the amount of equivalent $\mathrm{CO}_{2}$ saved, the energy mix in the Aragon region has to be considered. Thus, considering an emission factor of $0.385 \mathrm{~kg}$ of $\mathrm{CO}_{2}-\mathrm{e}$ per kWh of electricity [33], the emission to the atmosphere of around 27 tons of $\mathrm{CO}_{2}$ has been avoided. Besides, during this period, 1,214 $\mathrm{Nm}^{3}$ of hydrogen have been produced. As the average consumption of hydrogen when moving at $15.6 \mathrm{~km} \mathrm{~h}^{-1}$ is around $12 \mathrm{NI}$ $\min ^{-1}\left(3.6 \mathrm{Nm}^{3}\right.$ day $\left.^{-1}\right)$, considering a diesel specific rate of 15 I per $100 \mathrm{~km}$ in a typical agricultural car, and including the energy supplied by the battery when working in hybrid mode that needs to be recharged every day, the use of hydrogen in the FCHEV has saved the consumption of around 1,010 I of diesel. Considering a production factor of $2.539 \mathrm{~kg}$ 
of $\mathrm{CO}_{2}$-e per liter of diesel [34], the emission of 3 tons of $\mathrm{CO}_{2}$-e has been avoided.

Taking into account the efficiency of the different elements of the power-to-gas plant, the overall efficiency for the electricity conversion, from the PV panels to the vehicle wheels, can be estimated. It was obtained that, depending on the electricity used to produce the hydrogen, it ranges from $24.6 \%$ to $30.5 \%$. The upper limit is reached when the electricity to produce hydrogen is directly obtained from the PV panels (the conversion efficiency of the DC/AC STP inverters is $98.4 \%$ ), while the lower one corresponds to hydrogen produced from energy previously stored in the battery. In the last case, the efficiency of the battery inverters (95\%) and that of the charge and discharge processes $(85 \%)$ have to be included in the analysis.

\subsection{Performance of the hydrogen production and refueling plant}

The behavior of two pressure transducers, P2 (at the compressor inlet) and P5 (at the stationary GSS) of the hydrogen production and refueling plant, is shown in Fig. 11 a). The data correspond to a period of 3 hours (from 10:00 to 13:00) that includes the refilling of the stationary GSS with hydrogen produced by the electrolyzer and the refueling of the GSS of the hybrid electric vehicle.

As it can be observed, the period of each charging cycle is around 24 min., and the pressure at the inlet of the compressor changes from 15 bar to $29.5 \mathrm{bar}$, which is the set point fixed at the control system to prevent failures. The compressor operates during the descent ramp, while it remains off when this pressure increases. Close to $700 \mathrm{I}$ of hydrogen were stored at the stationary GSS during this test, increasing its pressure from 168 bar to 176 bar. The fast decrease in the pressure at the stationary GSS between minutes 174 to 175 is due to the refueling of the GSS of the FCHEV. A zoom for this time window is observed in Fig. 11 b) where this performance is clearly depicted. In the different tests performed, the fast refueling time of the WEH system was demonstrated. In this specific test, the GSS of the FCHEV is refilled from 30 bar to 157 bar in less than $20 \mathrm{~s}$ (dashed line), and the pressure at the stationary GSS of the hydrogen production station change in less than 14 bar, from 175.5 bar to 161.6 bar (solid line). From the tests performed, it was shown that the refilling frequency of the GSS of the FCHEV is every 1.5 days, while 11.5 hours are needed to refuel the used hydrogen in the stationary GSS. 


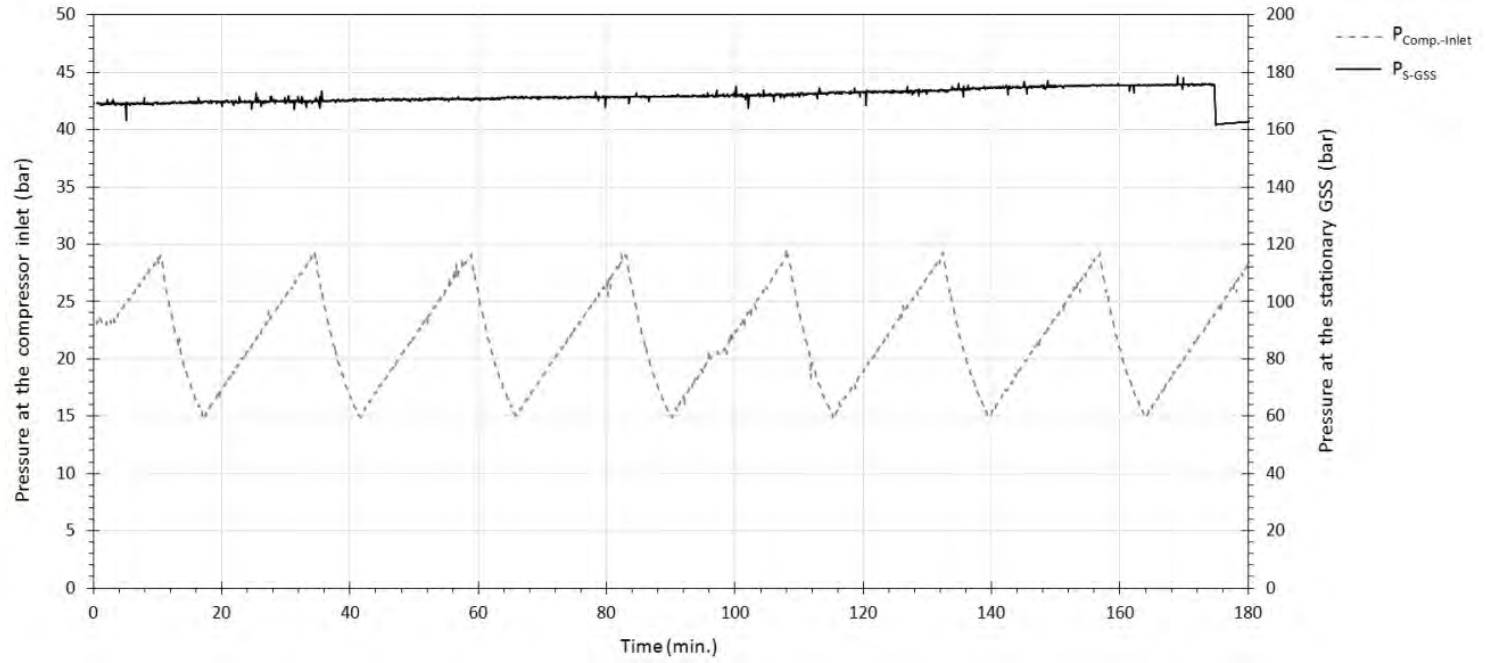

a)

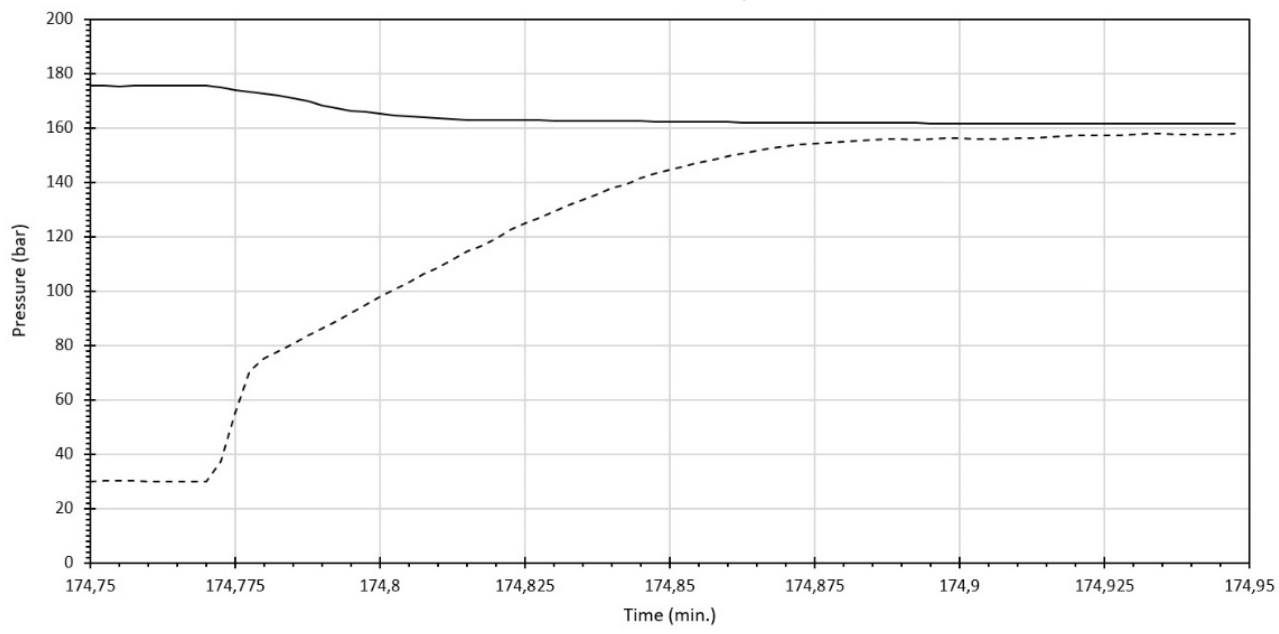

b)

Figure 11. Performance of both the system to refill hydrogen to the stationary GSS (a), and that to refuel hydrogen to the GSS of the FCHEV (b)

\subsection{Performance of the hybrid electric car}

Different field tests of the FCHEV were performed in real operating conditions at the winery. The results obtained during a real driving test are depicted in Fig. 12. It consisted in a round trip of $6 \mathrm{~km}$ that lasted around $24 \mathrm{~min}$, from the parking of the winery to the vineyards, climbing two small hills. The average velocity of the FCHEV during the whole test was $15.2 \mathrm{~km} \mathrm{~h}^{-1}$, reaching a maximum of $45 \mathrm{~km} \mathrm{~h}^{-1}$ with an average power demanded by the EM of the vehicle of $4.19 \mathrm{~kW}$. However, as can be observed in Fig 12 a), the peak power demanded by the EM (solid black line) when ascending the hills or during a fast acceleration exceeds, by far, the rated power of the electric motor $(7.5 \mathrm{~kW})$. For the high demand range, the power is mainly supplied by the battery (dashed line), while for the low power demand range the CHARGING mode at the $\mathrm{H}$ - 
3000 stack is activated and part of the energy is used to recharge the battery. This situation corresponds to the different zones in Fig. 12 a) where the power of the battery is negative. When working in hybrid mode, $74.8 \%$ of the total energy demanded by the vehicle was supplied by the battery and $25.2 \%$ by the PEMFC.

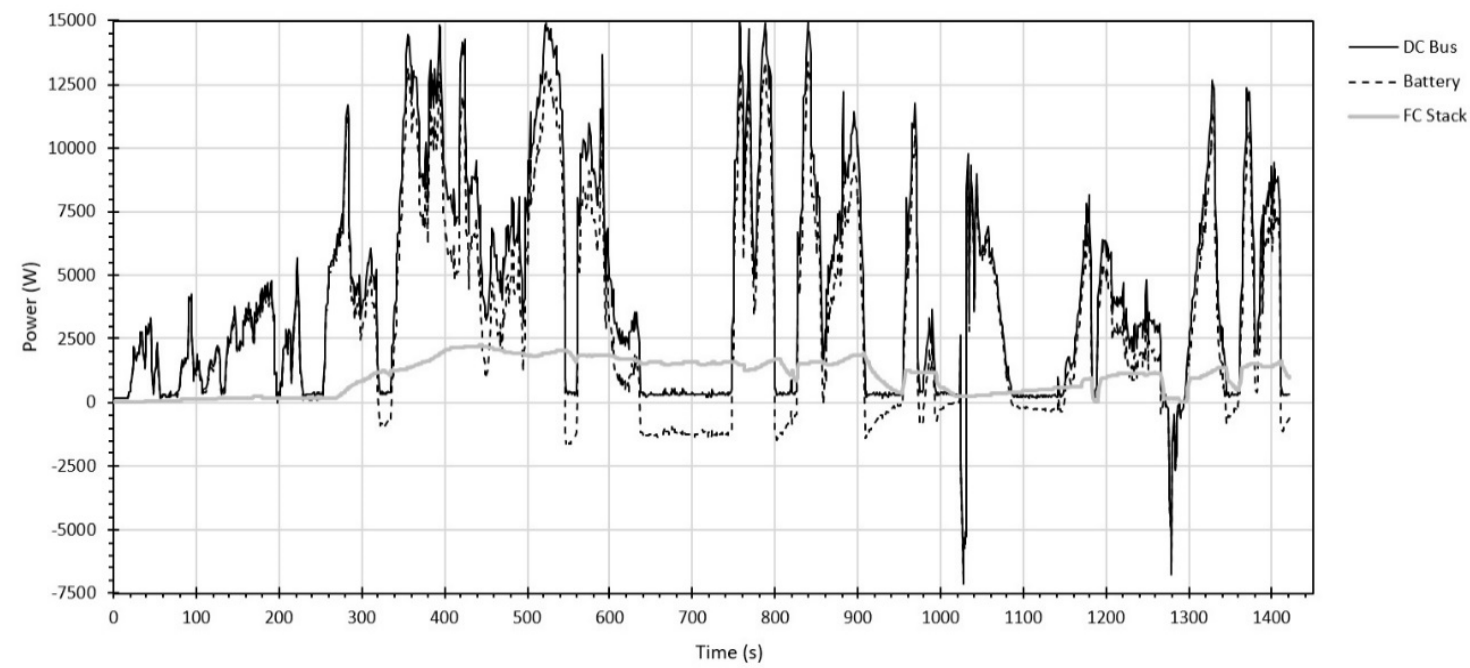

a)

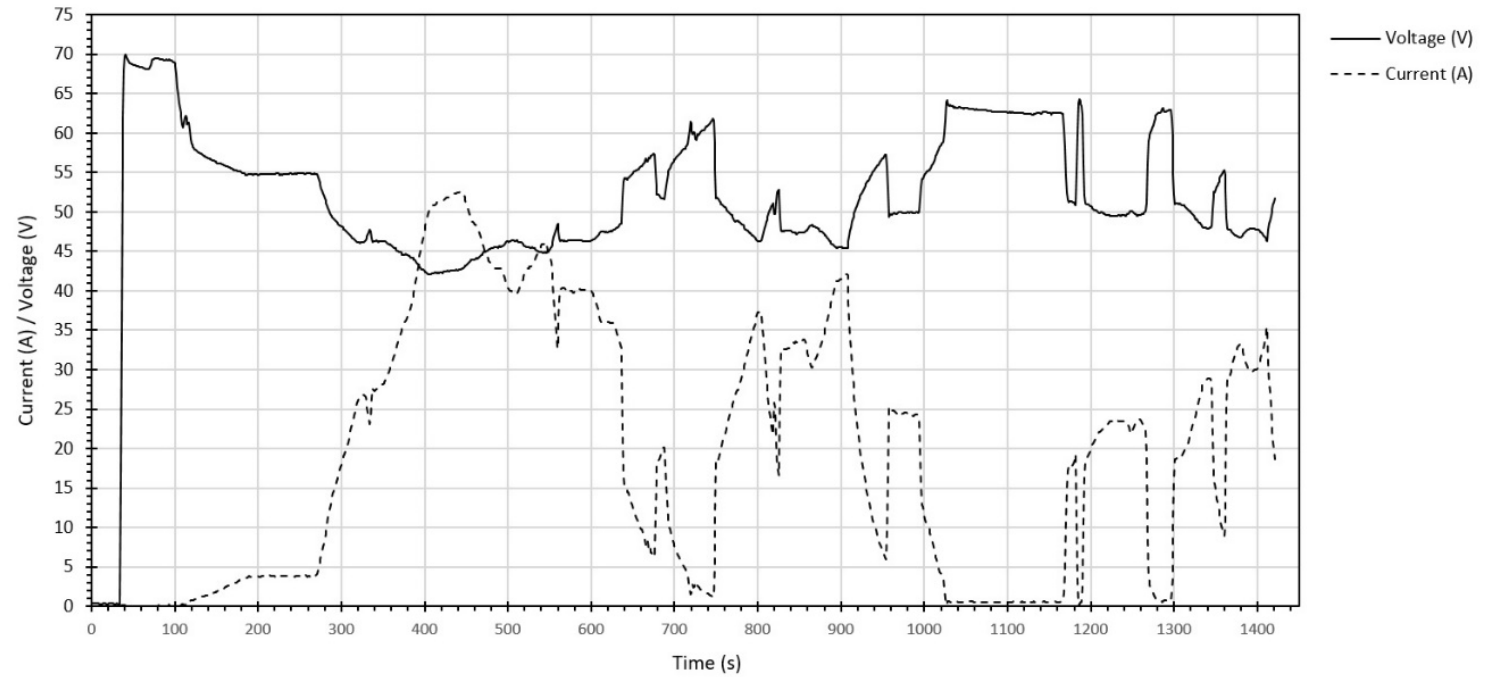

b)

Figure 12. Results of the real driving test in the winery: a) power of the different sources, and b) electric performance of the stack

On the other hand, the PEMFC stack works in a quasi-steady state (solid bold grey line), with an average power of $1.05 \mathrm{~kW}$ and a net efficiency of $51.4 \%$. This result shows the excellent performance of the stack control system, avoiding sudden changes in load that can damage the device due to its slow dynamics. The average voltage of the $\mathrm{H}-3000$ PEMFC stack in this test is $51.8 \mathrm{~V}$, and the average current reaches $20.3 \mathrm{~A}$, which 
corresponds to a current density of around $0.1 \mathrm{~A} \mathrm{~cm}^{-2}$ (see Fig $12 \mathrm{~b}$ ). An interesting result was to confirm that part of the kinetic energy of the FCHEV is recovered when braking, corresponding with the two narrow negative peaks of power in times 1,028 s and 1,280 s. This unexpected performance, not indicated by the manufacturer in the vehicle manual, occurs when the car is moving at a fast velocity (descending the second hill) and the traction system is shifted to the lowest gear. Under this condition, the DC/AC booster electronic converter of the EM can also work as a generator. Finally, it was also confirmed that the actual range of the vehicle was almost doubled, from 2.7 hours for the pure BEV to 4.8 hours of the hybrid one.

\subsection{Cost analysis of the electricity production}

Based on the publications of the Solar Energy Industry Association, the average price of a complete PV system has dropped by more than $70 \%$ since the beginning of 2011 [35]. It is important to highlight that the PV plant of this project is not a typical commercial facility, but it is a "demonstrative prototype". Obviously, the replication of the proposed solutions is cheaper than the prototype. In most cases a fixed array, which is the conventional technology, should only be considered. The inclusion of the tracking array and the floating panels increases the final cost, but it allowed showing and testing the performance of the three systems under the same operating conditions. The same demonstration purposes justified the incorporation of the hydrogen production facility and the fuel-cell-powered vehicle despite their high cost, but the production and use of hydrogen is not considered for this economic comparison.

In the cost analysis, the three technologies that are commonly used to supply electric power to the WWTP and to the pumping system for irrigation in the wine industry are compared. These are, namely, the commercial electric grid, a diesel-based generation set (genset), and the PV solar plant. It is noteworthy that the aim of the calculations is to compare the three solutions, because the supply of energy is needed in any case. The cost of all the equipment and the increase in fuel prices have been considered, using the data from the last 15 years. In the case of the PV facility, the costs inherent to the building work for the three arrays, the air conditioning system of the technical room, and the assembling of the whole plant are also included. Besides, a degradation rate of $1 \%$ is considered for the solar panels. To calculate the annual costs 
of the three technologies, the following equations are used,



$T A C_{D G}=I_{O-D G}+\left[\sum_{Y e a r=1}^{n} A E_{Y e a r}\left(1+I n f_{g e n}\right)^{Y e a r}+C o_{D G}\left(1+I n f_{D G}\right)^{Y e a r}+C o L_{D G}\right]$,

$T A C_{C E}=I_{O-D G}+\left[\left(\operatorname{CoE} \cdot E_{\text {cons }}\right)+\left(\operatorname{CoP} \cdot P_{\text {cons }}\right)+\right.$ Taxes $]\left(1+I n f_{C E}\right)^{Y e a r}$,

where TAC is the total annual costs $(€), l_{o}$ the initial investment costs $(€), A E$ the annual expenses $(€)$, Inf the inflation (\%), $\operatorname{CoL}$ the cost due to lifetime $(€), \operatorname{Co} E$ the energy cost $(€)$, CoP the power cost $(€), E$ the energy consumed (kWh), and $P$ the power consumed (kW). Subscript $P V$ refers to the solar $P V$ plant, $D G$ to the diesel genset, $C E$ to the electricity from the commercial grid, gen to general, Bat to the battery bank, and Inv to the inverters. Besides, the net present value (NPV) is calculated according to

$$
N P V=\sum_{Y e a r=1}^{n} \frac{C_{Y e a r}}{(1+k)^{\text {Year }}}-I_{O},
$$

in which $C$ is the yearly cash-flow, and $k$ is the annual discount rate considered (10\%). A summary of the main parameter used in the analysis is listed in Table 4.

\begin{tabular}{lccc}
\hline Parameters & Diesel genset & Electricity grid & PV solar plant \\
\hline Annual energy consumption $(\mathrm{kWh})$ & & $75,000.00$ & \\
Total electric power $(\mathrm{kW})$ & & 50 & \\
Fuel oil price $\left(€ \mathrm{I}^{-1}\right)$ & & 0.60 & \\
Initial investments (all costs included) & $18,500.00$ & $25,000.00$ & $181,854.00$ \\
Annual costs: & & & 250.00 \\
- Maintenance $(€)$ & $1,846.63$ & & \\
- Fuel oil $(€)$ & $11,079.00$ & & \\
- Electric energy index $\left(€ \mathrm{kWh}^{-1}\right)$ & & 0.11245 & \\
- Electric power index $\left(€ \mathrm{~kW}^{-1}\right)$ & & 45.7245 & \\
- Renting devices $(€)$ & & 343.35 & \\
- Taxes in Spain (€) & & 526.70 & \\
Inflation & & & \\
- General (\%) & 3.00 & 3.00 & \\
- Diesel (\%) & 3.20 & & \\
- Electricity (\%) & & 3.20 & \\
\hline
\end{tabular}

Table 4. Main parameters used in the cost analysis

The evolution of the annual costs of the three systems for the values considered in the study is presented in Fig. 13. The total cost of the PV solar system is almost constant because it is mainly affected by the initial investment cost $(181,854.00 €)$. Nevertheless, the maintenance cost, as well as the costs related to the lifetime of both the battery bank (12 years) and the inverters (15 years) have also been included in the analysis. A lifetime of 15 years, and its corresponding cost, was also considered for the diesel 
genset. As can be observed, from years 9.5 and 13 the costs of both the diesel-based generation system and the commercial electricity, respectively, are greater than the PV solar power system. A positive result of the NPV $(58,086.31 €)$ was only obtained for the PV solar power system, with an internal rate of return (IRR) of $13.44 \%$. The NPV values obtained for the diesel system and for conventional electricity are $-187,819.93 €$ and $-161,121.15 €$, respectively. So, the profitability of the PV solar power system is clearly demonstrated.

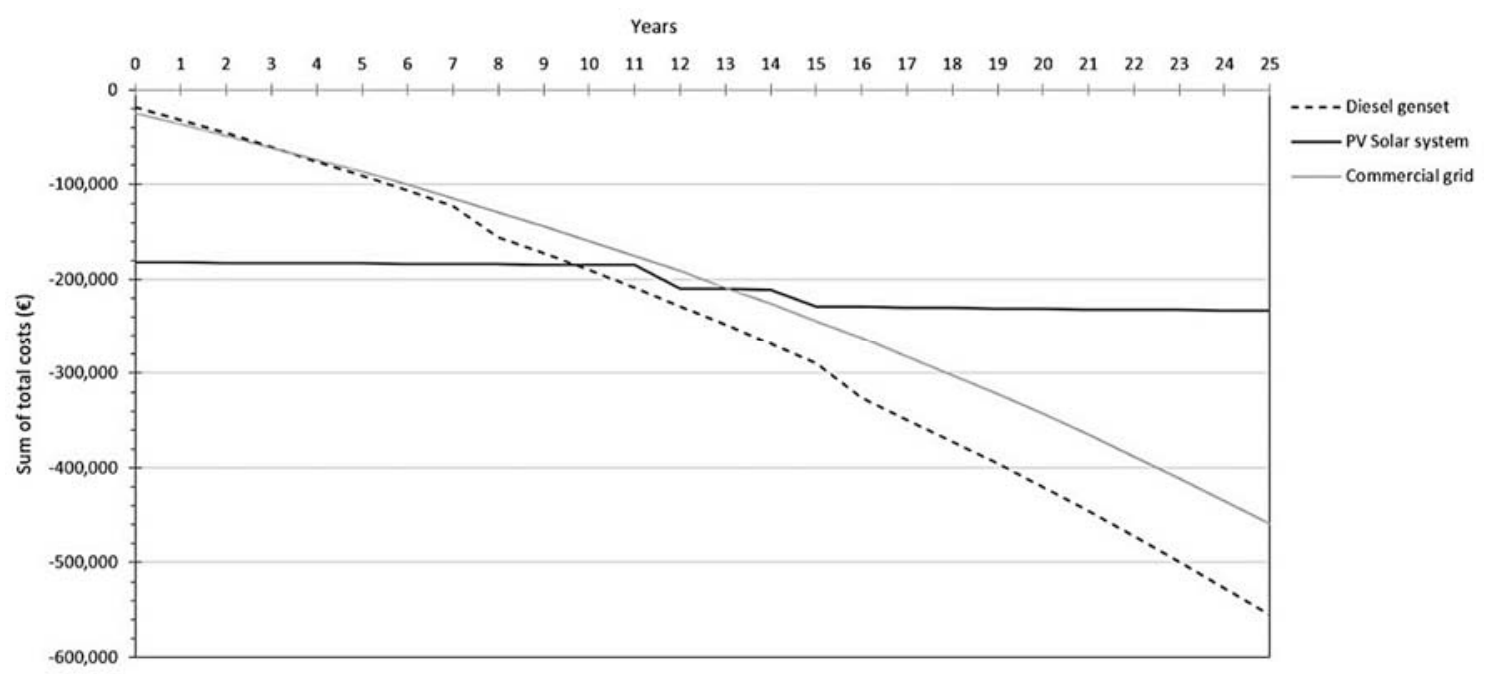

Figure 13. Cost analysis for the three technologies commonly used to produce electricity in the wine industry

\section{Conclusions}

The technical and economic feasibility of an isolated electrical plant from PV solar energy that eliminates both local diesel-based generation equipment and aerial power lines has been demonstrated in Viñas del Vero winery. With the facility developed in the present research, during the first year around $72 \mathrm{MWh}$ of electricity were produced, saving the emission of around 24 tons of $\mathrm{CO}_{2}$-e to the atmosphere. Besides, $6.4 \mathrm{MWh}$ have been employed to produce hydrogen in a generation and refueling station specifically designed and manufactured for this project. During the first year, 1,214 Nm of hydrogen have been produced, avoiding the emission of close to 3 tons of $\mathrm{CO}_{2}$-e. Field tests performed to the FCHEV proved that when working in hybrid mode around $30 \%$ of the total energy demanded was supplied by the PEMFC stack, which notably extend the original range. The excellent performance of the commercial WEH refueling system was also demonstrated. 
Considering the efficiency of the different elements of the system, the overall efficiency for the electricity conversion of the power-to-gas-to-power plant (from the PV panels to the vehicle wheels) ranges from $24.6 \%$ (when the electricity to produce hydrogen is directly obtained from the PV panels) to $30.5 \%$ (when the electricity is previously stored in the battery bank). Even when the present PV power plant is a demonstrative prototype, a positive result has been obtained for both the NPV and the IRR, demonstrating the profitability of the investment. This is a very important result to encourage the investment of private capital in the renewable energy sector.

\section{Acknowledgements}

This work has been funded by the European Union LIFE+ under project LIFE13 ENV/ES/000280, and by the Secretariat of State for Research of the Spanish Ministry of Economy and Competitiveness under project DPI2015-69286-C3-1-R (MINECO/FEDER, UE). Support of the Regional Government of Aragon to the Experimental Fluid Dynamics Research Group (TO3) of the LIFTEC is also acknowledged.

\section{References}

[1] G. Gahleitner, Hydrogen from renewable electricity: An international review of power-to-gas pilot plants for stationary applications, International Journal of Hydrogen Energy (2013) 38, 2039-2061

[2] Y.S. Mohammed, M.W. Mustafa, N. Bashir, Hybrid renewable energy systems for off-grid electric power. Review of substantial issues, Renewable and Sustainable Energy Reviews (2014) 35, 527-539

[3] S.E. Hosseini, M.A. Wahid, Hydrogen production from renewable and sustainable energy resources: promising green energy carrier for clean development, Renewable and Sustainable Energy Reviews (2016) 57, 850-866

[4] D. Scamman, M. Newborough, H. Bustamante, Hybrid hydrogen-battery systems for renewable off-grid telecom power, International Journal of Hydrogen Energy (2015) 40, 13876-13887

[5] F. Yilmaz, M. Tolga Balta, R. Selbaş, A review of solar based hydrogen production methods, Renewable and Sustainable Energy Reviews (2016) 56, 171-178

[6] X. Wu, X. Hu, S. Moura, X. Yin, V. Pickert, Stochastic control of smart home energy management with plug-in electric vehicle battery energy storage and photovoltaic 
array, Journal of Power Sources (2016) 333, 203-212

[7] D.B. Nelson, M.H. Nehrir, C. Wang, Unit sizing and cost analysis of stand-alone hybrid wind/PV/fuel cell power generation systems, Renewable Energy (2006) 31, $1641-1656$

[8] C. Wang, M.H. Nehrir, Power management of a stand-alone wind-photovoltaicfuel cell energy system, IEEE Transactions on Energy Conversion (2008) 23, 957967

[9] M. Uzunoglu, O.C.Onar, M.S. Alam, Modeling, control and simulation of a PV/FC/UC based hybrid power generation system for stand-alone applications, Renewable Energy (2009) 34, 509-520

[10] S. Mumtaz, L. Khan, Adaptive control paradigm for photovoltaic and solid oxide fuel cell in a grid-integrated hybrid renewable energy system, PLoS ONE (2017) 12(3), e0173966

[11] A. Andrijanovits, H. Hoimoja, D. Vinnikov, Comparative Review of Long-Term Energy Storage Technologies for Renewable Energy Systems, Electronics and Electrical Engineering (2012) 2(118), 21-26

[12] A. Yilanci, I. Dincer, H.K. Ozturk, A review on solar-hydrogen/fuel cell hybrid energy systems for stationary applications, Progress in Energy and Combustion Science (2009) 35, 231-244

[13] R. Mustata, V. Roda, A. Nueno, L. Valiño, A. Lozano, F. Barreras, J.L. Bernal, J. Carroquino, Small scale demonstration project for the production and use of hydrogen from renewable energy sources in the wine sector, Proceedings of the $21^{\text {st }}$ World Hydrogen Energy Conference, WHEC (2016) 383-384

[14] J. Carroquino, R. Dufo-López, J.L. Bernal-Agustín, Sizing of off-grid renewable energy systems for drip irrigation in Mediterranean crops, Renewable Energy 76 (2015) 566-574

[15] J. Aymamí, A. García, O. Lacave, L. Lledó, M. Mayo, S. Parés, Analysis of the resource. Wind Atlas of Spain. Technical Study PER 2011-2020, Spanish Institute for the Diversification and Saving of Energy (IDEA), Madrid, 2011 (in Spanish)

[16] Atlas of solar radiation in Spain, Meteorological Agency (AEMET), 2012, in: http://www.aemet.es/es/serviciosclimaticos/datosclimatologicos/atlas_radiacion_solar (in Spanish) 
[17] PVGIS - Online free solar photovoltaic electricity generator simulation and solar radiations maps. Consulted in July 2017 at the webpage: http://photovoltaicsoftware.com/pvgis.php

[18] E. Dursun, B. Acarkan, O. Kilic, Modeling of hydrogen production with a standalone renewable hybrid power system International Journal of Hydrogen Energy 37 (2012) 3098-3107

[19] D. Ghribi, A. Khelifa, S. Diaf, M. Belhamel, Study of hydrogen production system by using PV solar energy and PEM electrolyser in Algeria, International Journal of Hydrogen Energy 38 (2013) 8480-8490

[20] R. Lacko, B. Drobnič, M. Sekavčnik, M. Mori, Hydrogen energy system with renewables for isolated households: The optimal system design, numerical analysis and experimental evaluation, Energy and Buildings 80 (2014) 106-113

[21] T.C. Morales, V.R. Oliva, L.F. Velázquez, Hydrogen from renewable energy in Cuba, Energy Procedia 57 (2014) 867-876

[22] D. Laslett, C. Carter, C. Creagh, P. Jennings, "A large-scale renewable electricity supply system by 2030: Solar, wind, energy efficiency, storage and inertia for the South West Interconnected System (SWIS) in Western Australia", Renewable Energy, 113 (2017) 713-731

[23] A. Aly, S. S. Jensen, A.B. Pedersen, Solar power potential of Tanzania: Identifying CSP and PV hot spots through a GIS multicriteria decision making analysis, Renewable Energy 113 (2017) 159-175

[24] M.R. Maghami, S.N. Asl, M.E. Rezadad, N.A. Ebrahim, C. Gomes, Qualitative and quantitative analysis of solar hydrogen generation literature from 2001 to 2014, Scientometrics 105 (2015) 759-771

[25] S. Sonwani, R. Prasad, Low-cost renewable hydrogen production using solar photovoltaic panel, Current Science 111 (2016) 712-716

[26] Z. Su, S. Ding, Z. Gan, X. Yang, Analysis of a photovoltaic-electrolyser directcoupling system with a V-trough concentrator, Energy Conversion and Management 108 (2016) 400-410

[27] F. Barbir, Hydrogen Islands-Utilization of Renewable Energy for an Autonomous Power Supply, Hydrogen Science and Engineering: Materials, Processes, Systems and Technology 2 (2016) 1075-1096 
[28] F. Sayedin, A. Maroufmashat, S. Sattari, A. Elkamel, M. Fowler, Optimization of photovoltaic electrolyzer hybrid systems; taking into account the effect of climate conditions, Energy Conversion and Management 118 (2016) 438-449

[29] V. Dash, P. Bajpai, Power management control strategy for a stand-alone solar photovoltaic-fuel cell-battery hybrid system, Sustainable Energy Technology Assessments 9 (2015) 68-80

[30] iHOGA website. Available at: http://personal.unizar.es/rdufo/index.php?lang=en

[31] Sh. Sreekumar, A. Benny, Maximum power point tracking of photovoltaic system using fuzzy logic controller based boost converter, Proceedings of the IEEE International Conference on Current Trends in Engineering and Technology, ICCTET'13, Coimbatore, India (2013) 275-280

[32] V. Roda, J. Carroquino, L. Valiño, A. Lozano, F. Barreras, Remodeling of a commercial plug-in battery electric vehicle to a hybrid configuration with a PEM fuel cell, International Journal of Hydrogen Energy https://doi.org/10.1016/j.ijhydene.2017.12.171

[33] Bulletin of the energy situation in Aragon and the regional energy balances in the period 1998-2004. Department of Economics, Industry and Employment, Aragon's Institute of Statistics (IAEST), November 18 ${ }^{\text {th }}, 2016$, in Spanish

[34] Emission Factors. Carbon Footprint Registry, Compensation and absorption Projects for Carbon Dioxide, report of the Spanish Ministry of Agriculture and Fisheries, Food and Environment, version 9, July 2017, in Spanish

[35] Web site: http://www.seia.org/research-resources/solar-industry-data, consulted in August 2017 